\title{
Psychological Distress As A Mediator Variable Between Experienced Incivility From Supervisor And Coworker To Instigated Incivility
}

\author{
Metty Verasari1,a, Prof. Madya Hazalizah Hamzah,b \\ UUniversiti Pendidikan Sultan Idris, Perak, Malaysia; 2University Pendidikan Sultan Idris, Perak, Malaysia \\ a metty@mercubuana-yogya.ac.id ; b hazalizah@fppm.upsi.edu.my \\ ${ }^{*}$ Corresponding Author \\ Whatsapp Number [+62-81271914653]
}

How to cite: Verasari, M. \& Hamzah, H. (2019). Psychological Distress As A Mediator Variable Between Experienced Incivility From Supervisor And Coworker To Instigated Incivility. International Journal for Educational and Vocational Studies, 1(4), 368-372

\section{ARTICLE HISTORY}

Received: 15 May 2019

Revised: 8 June2019

Accepted: 23 July 2019

KEYWORDS

Psychological Distress;

Workplace Incivility;

Experienced Incivility;

Instigated Incivility;

\begin{abstract}
Workplace Incivility is a common phenomenon in many organizations workplaces. The necessary antecedent of workplace incivility consisted of the presence of two or more people, with one or more as the source of the incivility, and another or others as its target in the workplace. Understanding the concept of workplace incivility to hospital managers and other health care organizations are very important for organizational development. This study aimed to understand the effect of experienced incivility from the nurse's supervisor and coworker in the hospital. Including sacrificing the psychological well-being of workers to experience psychological stress. This psychological pressure can be stress, job dissatisfaction and can have a high level of burnout. The methodology to analyze is a diary study between 3 days on 102 nurses in Sumatra, Indonesia. The results of this study indicate that the psychological stress variable is not a variable between the experience of getting unpleasant treatment from superiors or work colleagues towards the emergence of impolite and intentional rude behavior.
\end{abstract}

This is an open access article under the CC-BY-SA license.

\section{INTRODUCTION}

Health services, especially the nursing profession, are considered vulnerable to experience workplace incivility. Nurses are demands to good in interact and treat patients for 24 hours (Asmuji, 2014; Prayogi, 2014). Unfortunately, the nurse's work environment is often accompanied by various types of discomfort, which may come from doctors, other nurses, patients or supervisors (Beattie \& Griffin, 2014; Vagharseyyedin, 2015). Nurses that exposed continuously to negative behavior can think that violence is part of their work so they are reluctant to report the incident (Christlevica, Joan, \& Ricky, 2016). That will influence nurses psychological well-being, change the way they provide health services or will be able to do violence.

Workplace incivility is a common phenomenon in various organizations. Zhou (2014), explained that workplace incivility is an unpleasant treatment, which is characterized by low intensity, intention to harm others, and contrary to norms in the workplace. The requirement for workplace incivility is the presence of two or more people, with one party being the perpetrator, and the other part being target or victim, and the possibility of third parties as spectators or eyewitnesses. The example of behavior is expressing rude comments, using humiliating tone, and talking unprofessionally to someone. This action certainly has a tremendous impact, both for individuals and organizations, but the awareness of this phenomenon, especially in Indonesia, is still fairly low.

Workplace incivility's climate affects the workers well-being because it exceeds the tolerance limits of stress levels in the workplace (Beattie \& Griffin, 2014). Unconsciously, workplace incivility has low intensity, so the negative interpersonal behavior that nurses experienced will be ignored by managers (Vagharseyyedin, 2015). This neglect has potentially detrimental effects on healthcare providers and patient safety (Elmblad, Kodjebacheva, \& Lebeck, 2014; Brooks, 2017). After experiencing aggressive behavior in the workplace, replying violently is a common response for victims who have a low attachment to work (Hershcovis, Parker, Reich, \& Bozeman, 2012).

The higher level of incivility occurs in the workplace will result in less healthy and satisfied staff, higher stress 
levels, and an increased risk of adverse consequences in a work environment. Employees' feelings of work will change, especially at the level of anxiety, comfort, depression, and enthusiasm. More frequency of incivility will increase greater emotions (negative emotions, guilt, sadness, fear/anxiety, and disgust), and bring retaliatory behavior, or intentional violence (Hershcovis, Parker, Reich, \& Bozeman, 2012; Bunk \& Magley, 2013; Vickous, 2015; Torkelson, Holm, Bäckström, \& Schad, 2016). This increase is a symptom of emotional fatigue, a condition that arises because of psychological and emotional demands on someone (Bacharach \& Conley, 1990; Hur, Kim, \& Park, 2015).

Generally, the source of workplace incivility comes from employers and coworkers. Incivility that carried out by superiors, has greater potential consequences and impacts on worse physical well-being (Lim et al., 2008; Lim \& Lee, 2011; Zhou, 2014). Leiter, Price, and Laschinger (2010) explained that incivility from supervisors in the workplace can lead to mistrust of the organization itself because it can be interpreted as workplace norms violating (Jiménez, Bregenzer, Leiter, \& Magley, 2018). The emergence of incivility from supervisors and coworkers is related to incitement to incivility, lower levels of welfare and job satisfaction, higher stress levels, and other demographic variables (Holm, 2014). Generation gaps also affect nurses psychological stress (Leiter et al., 2010). The younger generation experienced pressure which indicates worse health and well-being. When nurses experience a lot of disrespectful behavior from various sources (doctors, patients, coworkers, and supervisors) in the workplace, their level of work satisfaction and salary are decreased. Nurses tend to feel that their compensation is not adequate for the stress they faced

According to Bartlett, Bartlett and Reio (2008), incivility arises because of motive and trigger. The motive for the instigated incivilities is belief and personality. Insecurity in the workplace, dissatisfaction, and low attention to inappropriate behavior can be a form of belief (Salin, 2003). Whereas aggression, hostility, power, ego, and internal competition are personality traits that can be underlying of incivility (Cortina et al., 2001; Glendinning, 2001; Hornstein, 2003; Copy, 2003). While the trigger for incivil behavior is a response to rage, fear, and anger; lack of communication; leader's lack of assertiveness; and less competent leader or coworker (Berger, 2000; Alexander-Snow, 2004).

Although researches have begun with the literature review about the relationship between experienced incivility and negative outcomes, but the most part, is addressed why workplace incivility becomes negative outcomes, and in what situations experiences will become a negative outcome, and what the type of negative outcome will be related by others (Bunk \& Magley, 2013). Affect Event Theory (AET; Weiss \& Cropanzano, 1996) is the theoretical approach to address the gap from a literature review. Weiss and Cropanzano (1996) discussed the importance of appraisals and emotions in reaction to workplace events, how affective reactions to work events are related to their job-related attitudes and behaviors (Bunk \& Magley, 2013; Hur et al., 2015). It's mean that AET will be translated into the incivility literature, considering what characteristics of the uncivil event might trigger the appraisal/emotional reaction and how those reactions then lead to negative work states (Bunk \& Magley, 2013).

Another researcher Bunk and Magley (2013) discovers about AET explained, the status of the perpetrators will give the different impact of reaction emotion on targets. According to the study by Pearson, Andersson and Porath (2000) in the case of incivility, status has a crucial role, when instigators have more power than targets, targets may feel helpless to fend off this mistreatment. This study also found, 58\% instigator from higher status and someone will be more fear and sadness if they get incivility from higher status. Tiedens, Ellsworth, and Mesquita (cite in Bunk and Magley, 2013) explained that the effects of social hierarchies have on appraisals and emotions. Because of what they call "sentimental stereotypes." High-status workers are perceived more positively than low-status workers, and consequently, low-status workers are more likely to blame for negative events. Following from this, it seems likely that the status of the instigator relative to the target (i.e., perpetrator power) will play a role in the target's appraisal/emotional reaction to uncivil experiences.

The current study shows that negative emotions are mediating variable between experienced incivility and three distal outcomes (burnout, physical symptoms, and targets' own uncivil behaviors). Hur et al. (2015) found that emotional exhaustion plays a mediating role between coworker incivility and job satisfaction. Bacharach, Bamberger, and Conley (2006) defined emotional exhaustion is a state caused by psychological and emotional demands on people (Hur et al., 2015). The greater incivility frequency and perpetrator power are associated with greater emotionality (negative emotions, guilt, sadness, fear/anxiety, and disgust) and it turns associated with increased reciprocation (Bunk \& Magley, 2013). So from the study, there are differences between experienced incivility from supervisor and coworkers to the negative outcomes as a mediator variable, towards instigated incivility.

In other words, being part of a work environment where individuals feel unappreciated, frustrated is induced and individuals feel the need to respond in a similar way, can make individuals feel less satisfied by being part of that organization. A low mood among colleagues, and especially from supervisors, can also weaken and reduce self-confidence and pride in individual work efforts, where their sense of well-being can be reduced (Holm, 2014). So, this pattern needs to be described in the research form, which will use psychological distress as a mediator variable, in order to see the relationship between irreverence experienced and psychological distress.

According to Vagharseyyedin, (2015) research, understanding the concept of workplace incivility is critical to hospital managers and other health care organizations. 
It can be used to promote a healthy work environment for nurses and expected to improve their quality of life. Further benefits of this research are expected to be helpful managers to knowing the existence of workplace incivility in nurses, so managers will be able to take preventive measures to address workplace incivility in healthcare settings.

\section{METHOD}

The population of this study will be taken from the Regional General Hospital in Special Region of South Sumatera, Indonesia. Purposive sampling method is used as the sampling method by categorizing the subjects (1) a nurse with nursing certificate (2) willing to be a repondent of this study, (4) having working period more than 2 years, (5) minimum age of 20 years, male or female, and is a nurse who has been appointed as permanent employee at the hospital, (6) understanding the instruction in filling in questionnaire in this research, and willing to follow research process for five consecutive days. Before the respondents to be a subject of this study, 150 nurses that fulfill the category must be following a screening test by filling out General Hospital Incivility (GHI) and finally 102 nurses could be to sample of this research. The result a GHI is 0.865 , and $V=1.00$ ( $\mathrm{X} \geq 0.66$, its mean relevant), with the critical value of CVR is 0.496. Its mean that GHI Scale could be valid and reliable to be a screening test for this study.

Table 1. Respondent Socio-Demography

\begin{tabular}{ccc}
\hline Charateristics & Category & $\%$ \\
\hline gender & Male & 28 \\
& Female & 72 \\
& $<3$ years & 23 \\
Nursing Department & years & 31 \\
& $>5$ years & 46 \\
& Emergency departements & 34 \\
& Intensive Care Unit & 14 \\
& Outpatients & 6 \\
& Inpatients & 46 \\
\hline
\end{tabular}

Based on the data from the distribution of respondents, it is seen that the subject of the study consisted of 102 people, with most of the nurses were female (72\%), consisted of working in inpatient units (46\%), and had work period more than 5 years $(46 \%)$.

\section{Measures}

a. Experienced Incivility From Supervisor and Coworkers

The scale from Jiménez, Bregenzer, Leiter, and Magley (2018) consists of eight aitem measure the behavior of workgroup supervisors and coworkers, respectively (e.g., "Gossiped about you or your colleagues"). Answer scales range used only two answered Yes and No. The result of Conbrachs Alpha is $0.824(\alpha \geq 0.6)$, its mean that thid aitem is reliable (Kerlinger, 1979). With the significance more then $95 \%$. For the content validity this instrument used CVR from Lawshe (1975) cited in Azwar (2012), with the critical value 0.496 and value of CVR $0.82-1.00$ ( $\mathrm{X} \geq 0.66$, its mean relevant). The result of content validity experienced incivility from supervisor and coworkers is valid.

b. Instigated Incivility

This item adapted from Jiménez et al. (2018), with Yes and No answered, because measuring dailiy instigated incivility. The result from Validity and Reliability test, a is 0.934 and the critical value of CVR is 0.496 with $\mathrm{V}=$ $0.82-1.00$ ( $\mathrm{X} \geq 0.66$, its mean relevant). From the validity and reliability test, explained that eight items of instigated incivility is valid and reliable.

c. Psychological Distress

In this study used Psychological Distress scale from Andrews and Slade (2001). Nine aitems of Kessler-10, would be answered with 5 likert scale ranging from (1) strongly disagree to (5) strongly agree was used, so a low score indicated psychological distress and a high score indicated high psychological distress. From the test of validity and reliability, this scale $\alpha$ is 0.934 . Value of CVR is $0.45-1.00$, with critical value $0.495(0.33 \leq \mathrm{X}<0.66$, that is mean quiete relevan).

\section{RESULTS AND DISCUSSION}

To see how psychological distress mediates experienced incivility of supervisors and coworkers towards instigatedincivility, we do data analysis using SEM AMOS. The results obtained are shown in figure 1.

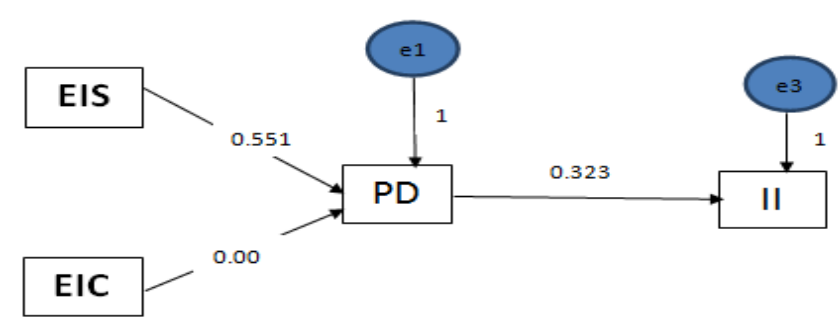

Figure 1. Experienced Incivility from the supervisor, Experienced Incivility from Coworkers, Psychological Distress, and Instigated Incivility.

As seen in figure 1, the regression coefficient of experienced incivility from the supervisor is obtained at 0.190 which means that if the variable experienced incivility from supervisor increases by 1 unit it will give an increase to the psychological distress variable of 0.190 units. The results of the significance test obtained sig. 0.551 value ( $>0.05$ ) which means that variables experienced incivility from supervisors have no significant effect on the psychological distress variable.

Furthermore, from Figure 1, it can be seen that the regression coefficient of experienced incivility from coworkers is obtained at 1.550 , which means that if the variable experienced incivility from coworkers increases by one unit, it will increase the psychological distress variable 
by 1,550 units. Results of the significance test obtained sig. 000 values $(p<0.05)$ which mean that variables experienced incivility from coworkers have a significant effect on the variable psychological distress.

Workplace deviance is a common response to workplace aggression. Specifically, victims will be more vulnerable to reply to abusive behavior, at higher level triggers, if they have low task interdependence (Hershcovis et al., 2012). Whereas experienced incivility from coworkers causes an increase in psychological distress. This is in accordance with a previous study from Beattie and Griffin (2014) that measurements per day showed that the level of stress respondents would be more increased if they get rude behavior. The study from Torkelson, Holm, Bäckström and Schad (2016) found that experienced incivility from coworkers has the strongest relationship on instigated incivility than a supervisor. Bunk and Magley (2013) also found that experienced incivility from coworkers has the strongest predictor of negative emotions than supervisors and the other source (physician and patient). Individuals were more likely to act in a deviant manner if they had information about deviant action by colleagues, particularly if group cohesion was high (Ferguson \& Barry, 2011). Leiter et al. (2010) also found that experienced incivility from supervisors and coworkers both had an impact on psychological distress, but the impact from experienced incivility from coworkers was more directed at the desire to withdraw from the environment with a cynical attitude, and the desire to directly take revenge on the supervisor, which eventually led to the desire to change work.

Holm, Torkelson and Bäckström (2015) found that having a socially supportive and controllable environment coupled with high amounts of incivility was connected with more instigated incivility. Then, social support from coworkers will decrease instigated incivility, but when variable experienced incivility was added, it will be increased instigated incivility. The psychological distress regression coefficient is 0.034 , which means that if the psychological distress variable increases by one unit, it will give an increase to the instigated incivility variable of 0.034 units. The results of the significance test obtained sig. 0.323 ( $>$ 0.05) which means that the psychological distress variable does not have a significant effect on instigated incivility variables. This result means that if nurses get experienced incivility from supervisors and coworkers, it can increase the level of psychological distress, but this does not directly affect the desire of nurses to instigate incivility.

Then from psychological distress to instigated incivility variables obtained at 0.034 which means that if the psychological distress variable increases by one unit, it will give an increase to the instigated incivility variable of 0.034 units. The results of the significance test are obtained for the sig value. $0.323(p>0.05)$ which means that the psychological distress variable has no significant effect on the instigated incivility variable. This proves that the psychological distress variable is not a mediating variable between experienced incivility and instigated incivility.

Although the psychological distress variables are not proven to be mediator variables between experienced incivility of supervisors and coworkers towards instigated incivility. But the impact of experienced incivility from supervisors and coworkers proved to have an impact on the emergence of negative emotions. Based on the analysis of the Affective Event Theory (Weiss \& Cropanzano, 1996) when workplace incivility causes a negative affective reaction to someone, it can turn to a negative impact in the long term in the future (Zhou, 2014). Quoted in Schilpzand, De Pater and Erez (2016), AET's focus is on affective reactions to events that occur in the workplace. According to this theory, events that occur in the workplace will become incitement depending on the individual characteristics of the employee, and affective reactions which in turn lead to certain attitudes and behaviors. Pearson, Andersson and Porath (2000), explain that considering the incivility experienced, there are three categories of behavioral responses that tend to focus on evaluating consequences, attribution, and more specific coping potential: (a) intended to reciprocate with agitators (i.e. aggression); (b) eliminate someone's frustration with others, including individuals and organizations (eg, movement); and (c) escape from the situation (eg, withdrawal). The conclusion is that AET can be used to explain negative emotions (psychological pressure and job satisfaction) as mediator variables between incivility experienced and triggered incivility.

According to research by Pearson, Andersson, and Porath (2000), it explains that when a person experienced workplace incivility, there are three categories of behavioral responses that focus on, consequences, attribution, and conducting strategic coping; which means (a) intended to reciprocate instigated incivility (i.e. aggression); (b) eliminate frustration, including individuals and organizations by career's and workplace's displacement; and (c) detach or withdraw from the situation. So the study shows that experienced incivility can cause negative effects and increasing the level of psychological distress.

Based on previous study, Beattie and Griffin (2014) found that individu had higher level of stress on days when they were treated in uncivil manner. This effects was above and beyond individuals general level of stress. The other study from Paulin and Griffin (2016) found that the team incivility climate had a direct negative relationship with employee well-being, over and above the individual level effect of incivility. In this study, job-related affective well-being refers to the emotionally employee feelings well or unwell in work related-context, this conditions also includes anxiety, comfort, depressions, and enthusiasm. However, the level of incivility to well-being, will be affected to employees which is work in a small team. And contrast, team size had no direct effect with well-being (Paulin \& Griffin, 2016). 


\section{CONCLUSION}

In this research, we find that experienced incivility by coworkers has an influence on psychological distress while experienced incivility from the supervisor isn't. We also found that the psychological distress variable does not have a significant effect on instigated incivility variables. If nurses get experienced incivility from supervisors and coworkers, it can increase the level of psychological distress, but this does not directly affect the desire of nurses to instigate incivility. Although the psychological distress variables are not proven to be mediator variables between experienced incivility of supervisors and coworkers towards instigated incivility. But the impact of experienced incivility from supervisors and coworkers proved to have an impact on the emergence of negative emotions.

\section{REFERENCES}

Andrews, G., \& Slade, T. (2001). Interpreting scores on the Kessler Psychological Distress Scale (K10). Australian and New Zealand Journal of Public Health, 25(6), 494-497.

https://doi.org/10.1111/j.1467-842X.2001.tb00310.x

Bacharach, S. B., \& Conley, S. C. (1990). Work Processes, Role Conflict, and Role Overload: The case of nurses and engineers in the public sector. Work and Occupations, 17(2), 199-228. https://doi.org/10.1177/0730888490017002004

Bartlett, J. E., Bartlett, M. E., \& Reio, T. G. J. (2008). Workplace Incivility: Worker and Organizational Antecedents and Outcomes. Online Submission, (2001). Retrieved http://files.eric.ed.gov/fulltext/ED501638.pdf

Beattie, L., \& Griffin, B. (2014). Day-level fluctuations in stress and engagement in response to workplace incivility: A diary study. Work \& Stress, 28(2), 124-142.

https://doi.org/10.1080/02678373.2014.898712

Bunk, J. A., \& Magley, V. J. (2013). The role of appraisals and emotions in understanding experiences of workplace incivility. Journal of Occupational Health Psychology, 18(1), 87-105.

https://doi.org/10.1037/a0030987

Christlevica, M., Joan, G., \& Ricky, D. (2016). Pengalaman Kekerasan Pada Perawat Instalasi Gawat Darurat. Jurnal Skolastik Keperawatan, 2(1), 20.

Elmblad, R., Kodjebacheva, G., \& Lebeck, L. (2014). Workplace Incivility Affecting CRNAs: A Study of Prevalence, Severity, and Consequences With Proposed Interventions. AANA Journal, 82(6), 437-445.

Ferguson, M., \& Barry, B. (2011). I Know What You Did : The Effects of Interpersonal Deviance on I Know What You Did : The Effects of Interpersonal Deviance on Bystanders. Journal of Occupational Health Psychology, 16(1), 80-94.

https://doi.org/10.1037/a0021708

Hershcovis, S., Parker, S. K., Reich, T., \& Bozeman, J. (2012). The relationship between workplace aggression and target deviant behaviour: The moderating roles of power and task interdependence. Work and Stress, 26(1), $1-20$. https://doi.org/10.1080/02678373.2012.660770

Holm, K. (2014). Workplace incivility as a social process: how witnessing incivility relates to uncivil conduct, well-being, job satisfaction and stress. Lunds Universitet.

Holm, K., Torkelson, E., \& Bäckström, M. (2015). Models of Workplace Incivility: The Relationships to Instigated Incivility and Negative Outcomes. BioMed Research International, 1-10.

https://doi.org/10.1155/2015/920239

Hur, W., Kim, B., \& Park, S. (2015). The Relationship between Coworker Incivility, Emotional Exhaustion, and Organizational Outcomes, The Mediating Role of Emotional Exhaustion. Human Factors and Ergonomics in Manufacturing \& Service Industries, 25(6), 701-712. https://doi.org/10.1002/hfm.2058

Jiménez, P., Bregenzer, A., Leiter, M., \& Magley, V. (2018). Psychometric properties of the German version of the workplace incivility scale and the instigated workplace incivility scale. Swiss Journal of Psychology, 77(4), 159-172. https://doi.org/10.1024/1421-0185/a000213

Leiter, M., Price, S., \& Laschinger, H. (2010). Generational differences in distress, attitudes and incivility among nurses. Journal of Nursing Management, 18(November), 970-980. https://doi.org/10.1111/j.1365-2834.2010.01168.x

Paulin, D., \& Griffin, B. (2016). The relationships between incivility, team climate for incivility and job-related employee well-being: a multilevel analysis. Work \& Stress, 30(2), 132-151.

https://doi.org/10.1080/02678373.2016.1173124

Pearson, C. M., Andersson, L. M., \& Porath, C. L. (2000). assesing and attacking workplace incivillity.pdf. Organnizational Dynamics, 123-137.

Schilpzand, P., De Pater, I. E., \& Erez, A. (2016). Workplace incivility, A review of the literature and agenda for future research. Journal of Organizational Behavior, 37(S1), S57-S88.

Torkelson, E., Holm, K., Bäckström, M., \& Schad, E. (2016). Factors contributing to the perpetration of workplace incivility : the importance of organizational aspects and experiencing incivility from others. WORK \& STRESS, 30(2), 115-131.

Vagharseyyedin, S. A. (2015). Workplace incivility: a concept analysis. Contemporary Nurse, 50(1), 115-125. https://doi.org/10.1080/10376178.2015.1010262

Vickous, K. E. Y. (2015). Perceptions of Incivility in Nursing Education : A Survey of Associate and Baccalaureate Program Nursing Students (Western Kentucky University Bowling). Retrieved from http://digitalcommons.wku.edu/diss/79

Zhou, Z. (2014). Effects of Workplace Incivility on Nurses' Emotions, Well-being, and Behaviors: A Longitudinal Study (University of South Florida). Retrieved from http://scholarcommons.usf.edu/etd/5338. 